\title{
Our moral obligations in caring for patients with orphan
} cancers

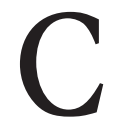
onsider a 6-year-old boy with metastatic neuroblastoma seeking experimental phase I chemotherapy, a 23-year-old woman with undifferentiated sarcoma that took 6 months of multiple physician visits to diagnose, or a 45-year-old man with breast cancer with no peer group support. Each is underserved by the Canadian health care system. They speak to the challenge of how we as a society define our values and distributive justice priorities for research and health care allocation in a fixed-budget environment.

More than 6000 rare diseases are defined generally by a frequency of less than I per 2000 population. ${ }^{1}$ Although these conditions are individually rare, they affect up to 25000 Canadians (one-third of whom are children). Indeed, all pediatric cancers and many uncommon adult cancers fit this definition. Adolescents and young adults with cancer have been recognized, in particular, as representing an orphan population with poor enrolment in clinical trials (especially young women with cancer), suboptimal outcomes and understudied cancer biology.

It is thought that the negative impact on survival and quality of life experienced by those with rare cancers may be rooted in delays in diagnosis, lack of access to specialized care, lack of peer support groups and/or inadequate therapeutic options. How we balance the dilemma of responsibly utilizing limited resources is an enormous ethical challenge. ${ }^{2}$ We must have public discourse and fair, open procedures that allow policy-makers to balance what we as a society owe children versus the elderly, how we manage limited resources in making end-of-life decisions, how we weigh evidence of benefit, and how we communicate these difficult decisions in compassionate ways. We are challenged to obtain this public voice from all constituencies and to synthesize it fairly.

There have been recent therapeutic successes in cancer care, but successes have been fewer for rarer diseases. Orphan drug development frequently lags behind that of more commercially viable agents. Even if a product is generated, it may be prohibitively expensive. Orphan drug legislation in the United States, Australia, Japan and the European Union provides a raft of incentives to stimulate the interest of pharmaceutical companies. These laws clearly advance drug development and have an effect on rare disease mortality.

The lack of a unified policy stipulated in law in Canada has been criticized, and it is hoped that the recently announced Canadian Partnership Against Cancer whose objectives are to reduce new cases of cancer, and enhance quality of life and re$\widetilde{\sigma}$ duce mortality of those with cancer, will advance the overall cancer control agenda, while remedying some of the inequities. In parallel, the National Pharmaceuticals Strategy interim report highlights 5 key priority areas: catastrophic drug coverage, expensive drugs for rare diseases, a common national formulary, pricing and purchasing strategies, and drug safety. ${ }^{3}$ This document provides laudable goals and recom- mendations, including a framework for expensive drugs for rare diseases that incorporates evidence, ethics ${ }^{4}$ and the need to align regulatory and reimbursement systems. A sense of urgency to their explication and adoption in practice is essential.

Although orphan drug development sometimes dominates discussion, patients with rare cancers suffer other injustices. How does one stimulate interest in conditions that may be encountered once every 5 years? Resources must be applied to improve competence in the recognition of rare cancers, to consolidate centres of excellence, to advance diagnostic timeliness and to maximize patient-centred resources. Funding agencies (both public, such as the Canadian Institutes of Health Research, and private) must specifically target inequities in research.

We should ensure that we strengthen home and community care - there is no point in placing all the emphasis on tertiary care without an appropriately resourced local and home environment. Although challenges in adequate home care are not always specific to orphan cancers, opportunities are more likely to be formulated in the programmatic care of more common disorders. Our Canada Health Act supports the concept that patients who require specialized care should not bear disproportionate financial burdens based solely on their happenstance of inconvenient geography.

Canadian policy-makers, with vital public input, must not ignore the difficult moral boundaries of our obligations to those with rare cancers, and indeed other rare diseases. These decisions need to be made in the context of physician responsibilities, economic viability, national equity and fairness in opportunity, and our global obligations, but with the individual person clearly in focus before us.

\section{Conrad V. Fernandez}

Departments of Pediatrics and Bioethics

IWK Health Centre and Dalhousie University

Halifax, NS

This article has been peer reviewed.

\section{REFERENCES}

I. van Weely S, Leufkens H. Orphan diseases. In: Priority Medicines for Europe and the World Project: "A public health approach to innovation." Department of Medicines Policy and Standards (PSM). World Health Organization. 2005. Available: mednet3.who.int/prioritymeds/report/background/rare_diseases.doc (accessed 2006 Dec I9).

2. Gericke CA, Riesberg A, Busse R. Ethical issues in funding orphan drug research and development. JMed Ethics 2005;31:164-8.

3. Federal/provincial/territorial Ministerial Task Force on the National Pharmaceuticals Strategy. National pharmaceuticals strategy progress report. Ottawa: Her Majesty the Queen in Right of Canada; 2006. Available: www.hc-sc.gc.ca/hcssss/alt_formats/hpb-dgps/pdf/pubs/2006-nps-snpp/2006-nps-snpp_e.pdf (accessed 2006 Dec ig).

4. MacPherson C, Kenny NP. Ethical issues in priority setting. Prepared for The National Pharmaceutical Strategy: Working Group on Expensive Drugs for Rare Diseases, August 2005. 